\title{
Charge-transfer spectra of ferrocene in halocarbon solvents under photoexcitation
}

\author{
ALFAZUDDIN THANDER and BISWANATH MALLIK* \\ Department of Spectroscopy, Indian Association for the Cultivation of \\ Science, Jadavpur, Calcutta 700 032, India \\ e-mail: spbm@mahendra.iacs.res.in
}

MS received 31 January 2000; revised 11 April 2000

\begin{abstract}
The changes in the electronic absorption spectra of ferrocene in the halocarbon solvents chloroform and carbontetrachloride have been investigated under photoexcitation in nitrogen atmosphere. Photoexcitations have been made with monochromatic light (using an Xe-source and a monochromator), at intervals of a few nanometers in the spectral range $220-750 \mathrm{~nm}$. Analysing the spectra by a modified method the position of the charge-transfer-to-solvent (CTTS) band has been located for both the solvents. The position of the CTTS band in the case of carbontetrachloride solution located $(320 \mathrm{~nm})$ by the present study is different from the previously reported value $(307 \mathrm{~nm})$, while from the previous studies the position of the CTTS band in the case of the spectra of ferrocene in chloroform was not clear. From the present investigation, the changes in spectra after photoexcitation studied as a function, the concentration of ferrocene in the solution and the time (duration) of photoexcitations, have been observed to be systematic. Using the position of the new band $(320 \mathrm{~nm})$ for the CTTS transition in the case of carbontetrachloride, ionization potential of ferrocene has been estimated and the estimated value has shown excellent agreement with the experimental value indicating the exactness of the newly located CTTS band position.
\end{abstract}

Keywords. Ferrocene; charge-transfer; halocarbon solvents; photoexcitation.

\section{Introduction}

Ferrocene (bis(cyclopentadienyl) iron: $\left(\mathrm{C}_{5} \mathrm{H}_{5}\right)_{2} \mathrm{Fe}$; abbreviated as $\mathrm{FcH}$, the first synthesized metallocene) has wide application in various technological fields ${ }^{1}$. The important electrochemical, photochemical and photophysical properties of the material have been recognized ${ }^{2-5}$. This material has been used (i) efficiently as mediators in various electron transfer processes ${ }^{2}$, (ii) in the development of biosensors ${ }^{2}$ and (iii) for the synthesis ${ }^{6}$ of new materials of higher electrical conductivity from poly (vinylidine chloride). Recent studies on the semi- and photoconductivity of this material under various experimental conditions have shown very interesting results ${ }^{7-9}$. Literature survey has shown that the studies on the change in electronic absorption spectra of ferrocene after photoexcitation (at several wavelengths in the UV region) in halocarbon solvents have received much attention in the past ${ }^{10-13}$. Formation of charge-transfer complexes of ferrocene with halocarbon solvents after photoexcitation (ferrocene- to solvent charge-

*For correspondence 
transfer (CTTS)) has been predicted by several research workers ${ }^{10-13}$. From the previous study ${ }^{12}$ the position of the CTTS band in the case of $\mathrm{CCl}_{4}$ solution was reported at $307 \mathrm{~nm}$ but the position of the CTTS band in the case of $\mathrm{CHCl}_{3}$ was not clear. The dissociation of the CTTS excited state to ferricenium cation was evidenced ${ }^{11,12}$ by the characteristic absorption band at $\approx 617 \mathrm{~nm}$. However, the earlier studies could not properly locate the position of the absorption band arising from the CTTS transition in the case of solutions of ferrocene in both $\mathrm{CCl}_{4}$ and $\mathrm{CHCl}_{3}$. This requires further studies on the topic. Study on the charge-transfer-to-solvent photochemistry are also a topic of current research as evidenced by the work of Tatistcheff et $\mathrm{al}^{14}$.

Previously, Brand and Snedden ${ }^{12}$ using the wavelength of $365 \mathrm{~nm}$ for excitation studied the effect of photoexcitation on the spectra of ferrocene in $\mathrm{CCl}_{4}$. Traverso and Scandola $^{11}$ used several wavelengths $(313,334,365,404$ and $472 \mathrm{~nm})$ for photoexcitation to study the effect of photoexcitation on the spectra of ferrocene in $\mathrm{CCl}_{4}$ and $\mathrm{CHCl}_{3}$ and they concluded that the irradiation in the spectral region where the ferrocene-to-halocarbon solvent charge transfer bands overlap the intramolecular bands caused the oxidation of ferrocene to ferricenium cation. From the previous limited experiment on photoexcitation the exact profile of the action spectrum for the photoinduced changes could not be obtained. Therefore, attempts were made to find out the exact profile of the action spectrum for the photoinduced changes using excitation wavelength at intervals of a few nanometers in the spectral range $220-750 \mathrm{~nm}$.

In the present study, the effects of photoexcitations (using monochromatic light) on the spectral behaviour have been studied in the nitrogen environment as a function of different parameters like exciting wavelength (at intervals of a few nanometers in the spectral range $220-750 \mathrm{~nm}$ ), the concentration of ferrocene in the solution and the time (duration) of light exposure. In the previous studies the spectra obtained after photoexcitations were analysed directly but in the present study instead of analysing the spectra obtained after photoexcitations, the difference in spectra expressed by the change in absorbance (i.e. absorbance after photoexcitation minus absorbance before photoexcitation) have been analysed to locate properly the positions of the new absorption bands. Analysing the spectra by the modified method as mentioned above, exact position of the charge-transfer-to-solvent (CTTS) band has been located for both the solvents. Using the new band position for CTTS transition in the case of carbontetrachloride, ionization potential of ferrocene has been estimated and the estimated value has shown excellent agreement with the experimental value indicating the exactness of the newly located CTTS band position. The results are presented in this article.

\section{Experimental}

High purity microcrystalline ferrocene in powder form was obtained from Strem Chemicals (Newburyport, MA, USA) and was used after further purification by repeated crystallization. Solvents used e.g., carbontetrachloride and chloroform were of spectrograde quality. The purity of the material was checked by usual spectral investigation.

Solution of ferrocene was made in the above-mentioned solvents. The irradiations were performed using $1 \mathrm{~cm}$ spectrophotometer cells filled with $\approx 3 \mathrm{ml}$ of solution at $\approx 300 \mathrm{~K}$ and using monochromatic light of various wavelengths in the range 220$750 \mathrm{~nm}$. Fresh solution was used for each experiment. For the studies on 
photoexcitations, the solutions were deoxygenated by saturation with pure and dry nitrogen gas. For removing the dissolved oxygen from the solution, dry nitrogen gas was allowed to bubble through (for about $15 \mathrm{~min}$; using glass capillary) the sample solution kept in the quartz cell before photoexcitation and then photoexcitation was carried out under the presence of nitrogen gas flow also. In our experimental conditions in pure solvents no clouding of solution was observed for at least initial one hour after photoexcitation. However, if the solution was kept for a long time (several hours) a little precipitation was noticed at the bottom of the sample cell. The electronic absorption spectra were recorded before and after the photoexcitation by using a UV-Vis Scanning Spectrophotometer, Model UV-2101 PC (Shimadzu, Japan). The resolution of the monochromator of this spectrophotometer is $0.1 \mathrm{~nm}$. A Xe-source operated at $60 \mathrm{~W}$ (Spectral Energy, USA) and a monochromator (type-H-20 UV, Ins. SA, division: Jobin Yvon, France) were used for obtaining radiation of different monochromatic wavelengths. The error limit involved in the excitation wavelength is $\sim 0.2 \mathrm{~nm}$ and the slit width used during photoexcitation was $2 \mathrm{~mm}$ for all the cases. For the excitation with visible light, a glass filter was used in the path of the excitation beam before the monochromator to eliminate the second order diffraction light (UV) from the monochromatic light in the visible range. A Luxmeter (Model: 5011, Aplab, India) was used to estimate the photon flux of the excitation beam reaching the sample solution. Maximum photon flux (corresponding to $\lambda=290 \mathrm{~nm}$ ) reaching the sample cell was $\sim 8.6 \times 10^{16}$ quanta $/ \mathrm{m}^{2} / \mathrm{s}$.

\section{Results and discussion}

Solutions of ferrocene in $\mathrm{CHCl}_{3}$ or $\mathrm{CCl}_{4}$ in the dark are stable for long periods and this phenomenon has been identified by spectral analysis. It has been reported ${ }^{3,11}$ that if solutions of ferrocene in $\mathrm{CHCl}_{3}$ or $\mathrm{CCl}_{4}$ are irradiated with $\mathrm{UV}$ radiation of proper wavelength, photooxidation of ferrocene occurs. We have studied systematically the effects of irradiation of both ultraviolet and visible light. The electronic absorption spectra of ferrocene in $\mathrm{CHCl}_{3}$ and $\mathrm{CCl}_{4}$ solvents before as well as after photoexcitation with UV light are shown in figure 1 . For the solution of ferrocene in $\mathrm{CHCl}_{3}$, the electronic absorption spectrum before photoexcitation (curve 1, figure 1) shows a broad band at $\approx 440 \mathrm{~nm}$ and in this case the appearance of the band in the UV region is not clear but there is an indication of a very weak shoulder at $\approx 325 \mathrm{~nm}$. The effects of the irradiation $(5 \mathrm{~min})$ of UV light, at $285 \mathrm{~nm}$, on the solution of ferrocene in $\mathrm{CHCl}_{3}$ are shown in curve 2, figure 1. Sample solution in $\mathrm{CCl}_{4}$ before photoexcitation shows (curve 3 , figure 1 ) one broad band at $\approx 440 \mathrm{~nm}$ and another band at $\approx 307 \mathrm{~nm}$. The effects of the irradiation of $\mathrm{UV}$ light $(10 \mathrm{~min})$, at $320 \mathrm{~nm}$, on the solution of ferrocene in $\mathrm{CCl}_{4}$ are shown in curve 4 , figure 1 . From figure 1 it is seen that intensity of the spectra after photoexcitation increases significantly in the UV region, compared to the visible region. In addition, appearance of a new band at longer wavelength side (at $\approx 620 \mathrm{~nm}$ ) is clear from figure 1 . In figure 2 the difference in spectra, expressed by the change in absorbance (i.e. absorbance after photoexcitation minus absorbance before photoexcitation) as a function of wavelength is shown for both the solvents. From figure 2, appearance of new peaks and shoulders in the spectrum for both the solvents are clear. Thus, figure 2 demonstrates clearly the effects of irradiation of UV light upon the solution of $\mathrm{CHCl}_{3}$ and $\mathrm{CCl}_{4}$ on the basis of spectral changes. From curve 1 in figure 2 it is observed that the spectrum for $\mathrm{CHCl}_{3}$ shows three new sharp absorption bands at $\approx 290,362$ and $620 \mathrm{~nm}$ 


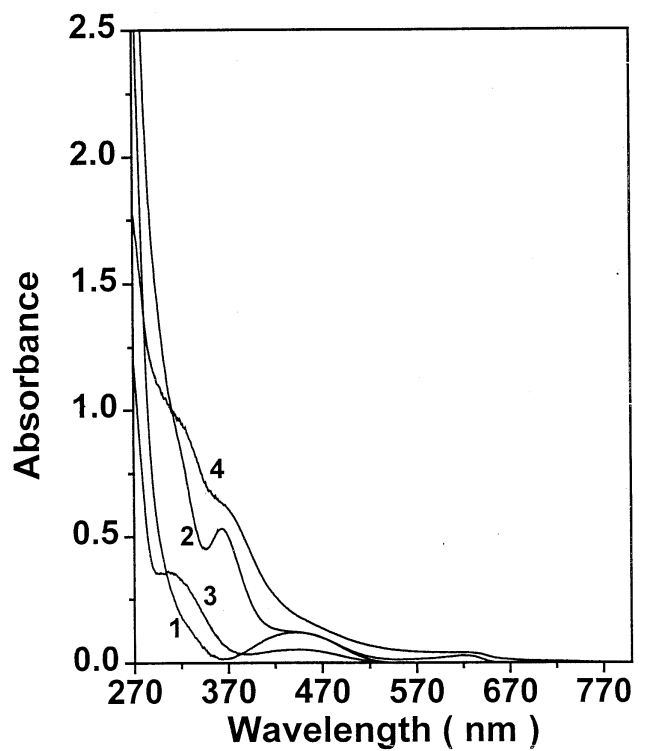

Figure 1. Electronic absorption spectrum of ferrocene in $\mathrm{CHCl}_{3}$ and $\mathrm{CCl}_{4}$ solutions before and after photoexcitation: 1 , in $\mathrm{CHCl}_{3}$ (concentration. $6.8 \times 10^{-4} \mathrm{M}$ ) solution before photoexcitation; 2 , in $\mathrm{CHCl}_{3}$ solution after photoexcitation by $285 \mathrm{~nm}$ for $5 \mathrm{~min}$; 3 , in $\mathrm{CCl}_{4}$ (concentration $2.04 \times 10^{-4} \mathrm{M}$ ) solution before photoexcitation and 4 , in $\mathrm{CCl}_{4}$ solution after photoexcitation by $320 \mathrm{~nm}$ for $10 \mathrm{~min}$.

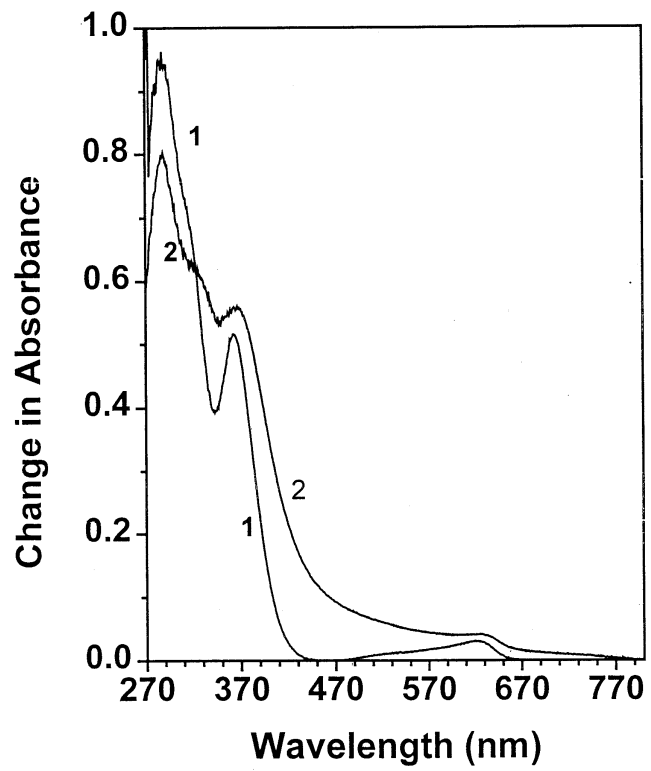

Figure 2. Change in absorbance versus wavelength for solutions of ferrocene in $\mathrm{CHCl}_{3}$ (concentration $6.8 \times 10^{-4} \mathrm{M}$ ) and $\mathrm{CCl}_{4}$ (concentration $2.04 \times 10^{-4} \mathrm{M}$ ) obtained after photoexcitation by UV light $\left(285 \mathrm{~nm}\right.$ for $\mathrm{CHCl}_{3}$ and $320 \mathrm{~nm}$ for $\mathrm{CCl}_{4}$, excitation time $5 \mathrm{~min}$ for $\mathrm{CHCl}_{3}$ and $10 \mathrm{~min}$ for $\left.\mathrm{CCl}_{4}\right) ; 1$, for $\mathrm{CHCl}_{3}$ and 2, for $\mathrm{CCl}_{4}$. 


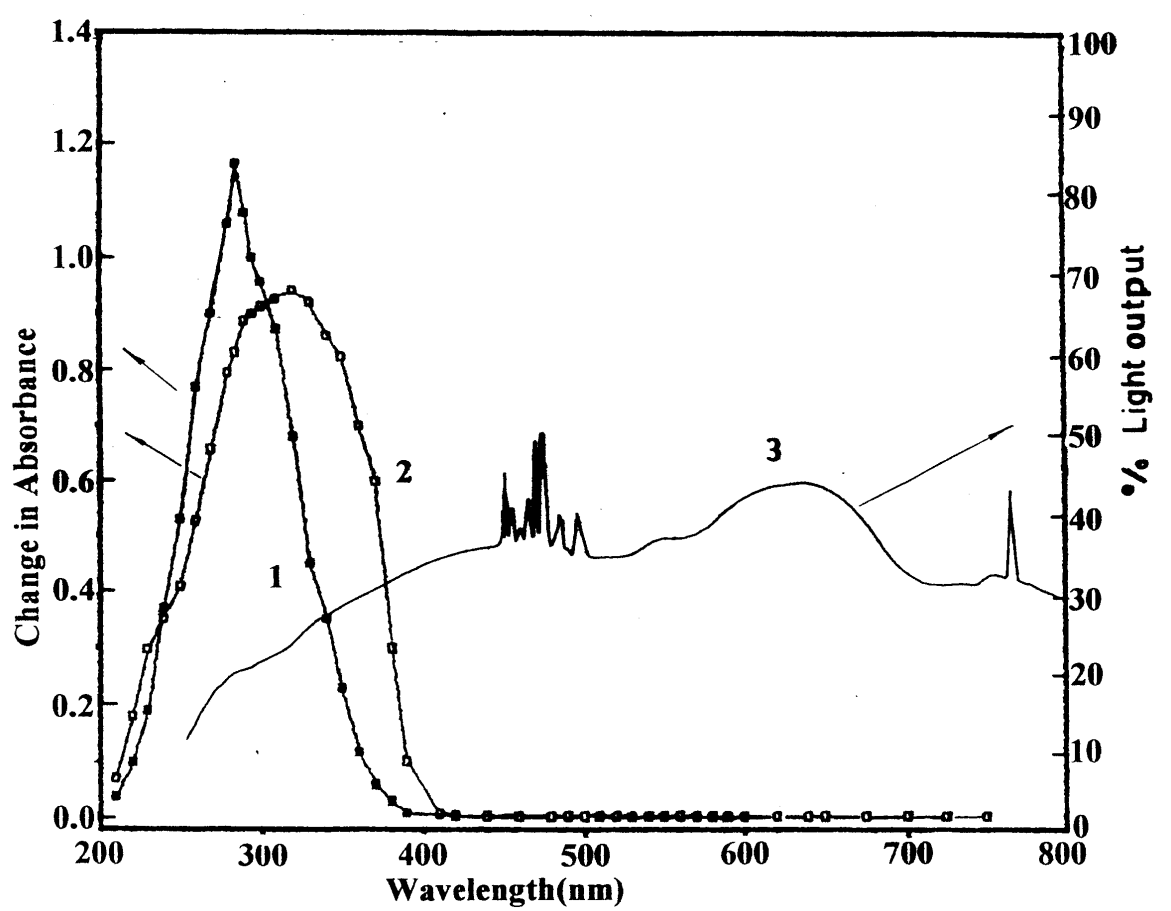

Figure 3. Plot of the change in absorbance of the band at $\left(362 \mathrm{~nm}\right.$ for $\mathrm{CHCl}_{3}$ and $367 \mathrm{~nm}$ for $\mathrm{CCl}_{4}$ ) versus exciting wavelength studied for solutions of ferrocene in $\mathrm{CHCl}_{3}$ (1) and $\mathrm{CCl}_{4}(2)$. Concentration of ferrocene $6.8 \times 10^{-4} \mathrm{M}$. Photoexcitation for 10 min. Curve 3 , intensity profile of xenon lamp

and two shoulder bands around 315 and $530 \mathrm{~nm}$. The curve 2 in figure 2 for $\mathrm{CCl}_{4}$ shows four clear absorption peaks at $\approx 290,320,367$ and $627 \mathrm{~nm}$ and one weak shoulder at $\approx 530 \mathrm{~nm}$ in the spectrum.

The effects of photoexcitation on the electronic absorption spectra of ferrocene in $\mathrm{CHCl}_{3}$ and $\mathrm{CCl}_{4}$ were studied as a function of exciting wavelength at intervals of a few nanometres in the spectral range $220-750 \mathrm{~nm}$. The change in absorbance of the new bands as a function of exciting wavelength was checked and such a plot for the change in absorbance of the band at $362 \mathrm{~nm}$ as a function of exciting wavelength is shown in figure 3 . This figure shows that the photoeffects depend drastically on the exciting wavelength. The curves 1 and 2 in figure 3 demonstrate clearly the profile of the action spectrum for the photoinduced changes in the case of ferrocene- $\mathrm{CHCl}_{3}$ and ferrocene- $\mathrm{CCl}_{4}$ systems, respectively. In the UV region the maximum intensity of the photoinduced changes was observed for irradiation at about 285 and $320 \mathrm{~nm}$ for $\mathrm{CHCl}_{3}$ and $\mathrm{CCl}_{4}$, respectively. The action spectrum is broad for the ferrocene- $\mathrm{CCl}_{4}$ interaction and the action spectrum for the ferrocene- $\mathrm{CHCl}_{3}$ interaction is comparatively sharp. The profile of the action spectrum is possibly related to the solvent effects. Similar results were obtained for other absorption bands also. However, for both the solvents no changes in the spectra were observed for photoexcitation with visible light. The Xenon lamp intensity profile, shown in figure 3 (curve 3), helps to understand the action spectra shown in figure 3 (curves 1 and 2). In the visible region, although the light output (curve 3 in figure 3 ) from the 
xenon lamp used for photoexcitation is significantly high, the photoinduced changes for excitation in the visible region were completely inefficient.

The changes in the spectra of ferrocene (upon photoexcitation) as a function of concentration of ferrocene in the solution as well as the time (duration) of photoexcitation were studied and observed to be systematic. Some representative results related to the changes in the spectra of ferrocene (upon photoexcitation) as a function of concentration of ferrocene in the $\mathrm{CHCl}_{3}$ and $\mathrm{CCl}_{4}$ solvents are discussed in the following paragraph.

The dependence of the intensity of the new bands that appeared on photoexcitation, upon the concentration of ferrocene in the halocarbon solvents was studied keeping the photo-exciting wavelength as well as duration of excitation fixed. With increasing concentration of ferrocene from lower values, a gradual increase in the intensity of all the new bands was observed as shown in figure 4 a for $\mathrm{CCl}_{4}$ (photoexcited at $320 \mathrm{~nm}$ for $10 \mathrm{~min})$. The changes in absorbance of the band at $362 \mathrm{~nm}$ with the concentration of ferrocene in $\mathrm{CHCl}_{3}$ are shown in the curve 1 of figure $4 \mathrm{~b}$ and the changes in absorbance of the band at $367 \mathrm{~nm}$ with concentration of ferrocene in $\mathrm{CCl}_{4}$ are shown in the curve 2, figure $4 \mathrm{~b}$. In general, figure $4 \mathrm{~b}$ shows that for the higher values of concentrations of ferrocene the intensity of the absorption bands attained almost a saturation value for both $\mathrm{CHCl}_{3}$ (saturation value: $6.8 \times 10^{-4} \mathrm{M}$ ) and $\mathrm{CCl}_{4}$ (saturation value: $8.8 \times 10^{-4} \mathrm{M}$ ). Similar plots as in figure $4 \mathrm{~b}$ were obtained for other new bands also. The observed change in the absorbance as a function of concentration of ferrocene is similar in nature as observed in standard plots of change in absorbance of CT bands with concentration of donor or acceptor in a standard CT complex.
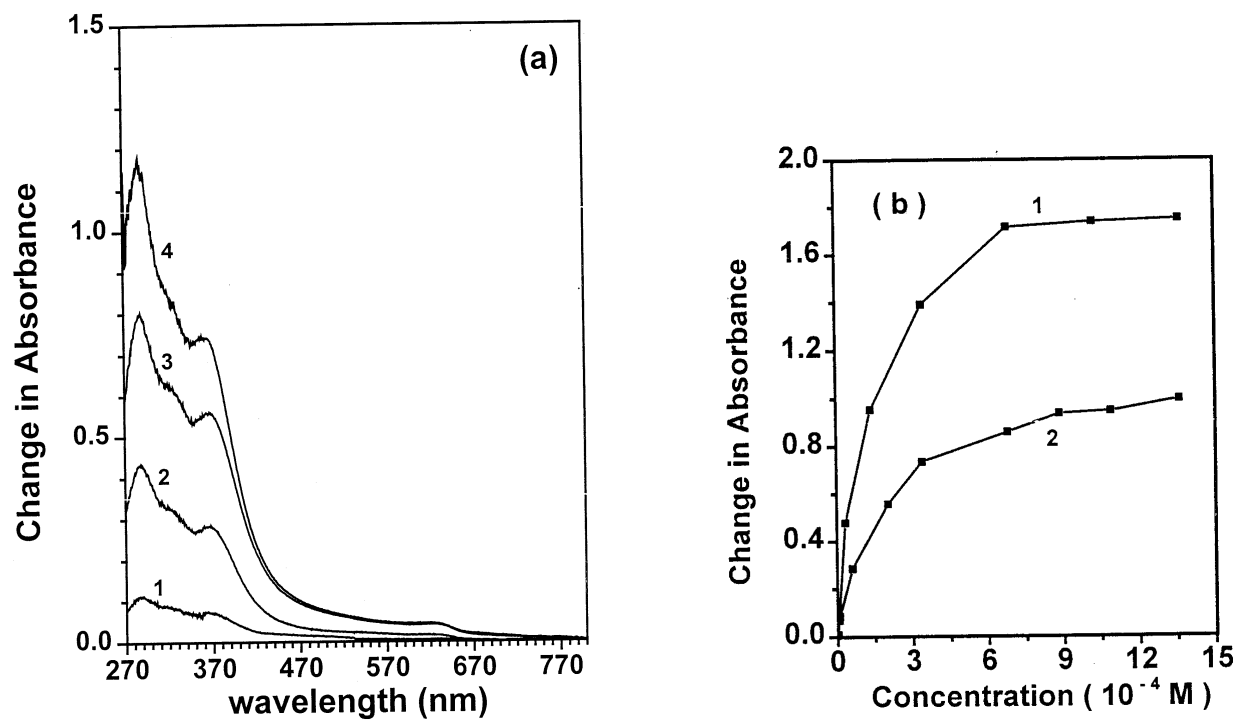

Figure 4(a). Plot of the change in absorbance versus wavelength studied for ferrocene solution in $\mathrm{CCl}_{4}$ as a function of concentration of ferrocene using photoexcitation by $320 \mathrm{~nm}$ for $10 \mathrm{~min}$. 1-4, refer to concentrations of $6.1 \times 10^{-6}$, $6.1 \times 10^{-5}, 2.04 \times 10^{-4}$ and $3.4 \times 10^{-4} \mathrm{M}$, respectively. (b) Plot of the change in absorbance of the band (at $362 \mathrm{~nm}$ for $\mathrm{CHCl}_{3}$ and $367 \mathrm{~nm}$ for $\mathrm{CCl}_{4}$ ) versus concentration of ferrocene solutions in $\mathrm{CHCl}_{3}$ (curve 1) and $\mathrm{CCl}_{4}$ (curve 2) for photoexcitation $\left(10 \mathrm{~min}\right.$ ) at $285 \mathrm{~nm}$ for $\mathrm{CHCl}_{3}$ and at $320 \mathrm{~nm}$ for $\mathrm{CCl}_{4}$. 

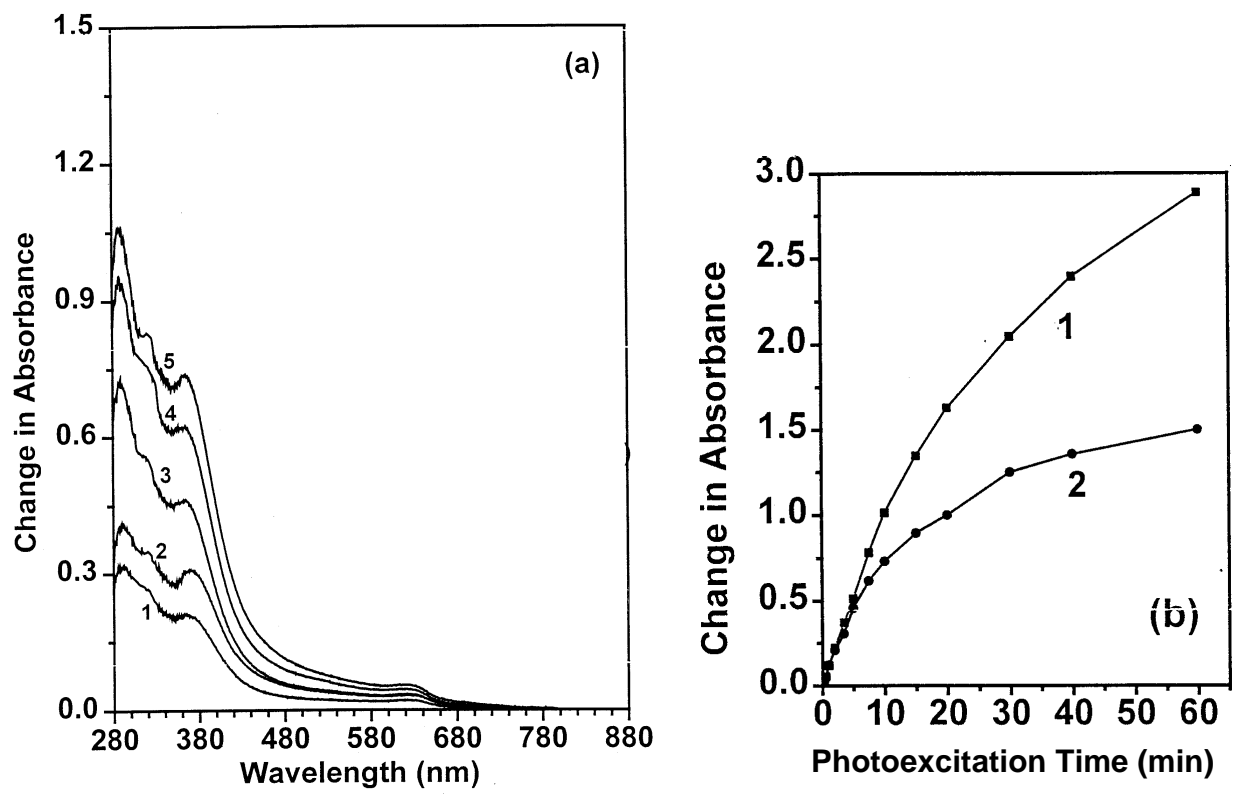

Figure 5(a). Change in the electronic absorption spectra of ferrocene in $\mathrm{CCl}_{4}$ solution (deoxygenated; concentration: $6.8 \times 10^{-4} \mathrm{M}$ ) for different time durations of photoexcitation by $320 \mathrm{~nm}$. Curves $1-5$ refer to photoexcitation time 2, 3.5, 5, 7.5 and 10 min respectively. (b) Plots of the change in absorbance of the band (at $362 \mathrm{~nm}$ for $\mathrm{CHCl}_{3}$ and $367 \mathrm{~nm}$ for $\mathrm{CCl}_{4}$ ) versus photoexcitation time. Curve 1 , for ferrocene in $\mathrm{CHCl}_{3}$ solution (deoxygenated, photoexcited by $285 \mathrm{~nm}$ for $10 \mathrm{~min}$ ). Curve 2, for ferrocene in $\mathrm{CCl}_{4}$ solution (deoxygenated, photoexcited by $320 \mathrm{~nm}$ for $10 \mathrm{~min}$ ). Concentration: $6.8 \times 10^{-4} \mathrm{M}$.

The variation in the electronic absorption spectra of ferrocene in halocarbon solvents with time (duration) of photoexcitation by UV light was studied. Enhancement in the intensity of the absorption bands with time of photoexcitation was noticed as shown in figure $5 \mathrm{a}$ for $\mathrm{CCl}_{4}$ for excitation by $320 \mathrm{~nm}$. Similar results related to the time of photoexcitation were obtained for $\mathrm{CHCl}_{3}$ also. In figure $5 \mathrm{~b}$, plots of change in absorbance of the band at $362 \mathrm{~nm}$ vs. time of photoexcitation are represented for $\mathrm{CHCl}_{3}$ by curve 1 . The curve 2 of figure $5(\mathrm{~b})$ represents the plot of the change in the absorbance at $367 \mathrm{~nm}$ vs. time of photoexcitation for $\mathrm{CCl}_{4}$. From the curves 1 and 2 in figure $5 \mathrm{~b}$ it is seen that the change in absorbance increases linearly with increasing time of photoexcitation up to about $10 \mathrm{~min}$ and for higher values of excitation time such linear relationship does not hold good. Similar plots as in figure $5 \mathrm{~b}$ were obtained for other new bands also. The results show that the kinetics of photoinduced changes is of first order for the photoexcitation of smaller duration (up to $\approx 10 \mathrm{~min}$ ). From the nature of the variation (as a function of time of photoexcitation) of the absorbance of the new bands in the electronic absorption spectra of ferrocene in halocarbon solvents obtained after photoexcitation, it appears that the photoinduced changes are systematic and must have some physical basis.

It has already been mentioned earlier that the new bands in the electronic absorption spectra of ferrocene (at room temperature) in the solutions of $\mathrm{CHCl}_{3}$ after photoexcitation 
appear at $\approx 290,315,362,530$ and $620 \mathrm{~nm}$. Similarly, in the case of $\mathrm{CCl}_{4}$, after photoexcitation the new bands in the spectrum appear at $\approx 290,320,367,530$ and $627 \mathrm{~nm}$. Scott and Becker originally reported ${ }^{15}$ a weak absorption band (shoulder) of ferrocene at about $528 \mathrm{~nm}$ in few solvents and they assigned this band as a spin forbidden singlet-triplet absorption corresponding to the forbidden singlet-singlet absorption at $324 \mathrm{~nm}$. It should be mentioned here that other investigators have studied the absorption spectra of ferrocene at room temperature. Other investigators have not reported the shoulder at $528 \mathrm{~nm}$. In the present study also the shoulder at about $528 \mathrm{~nm}$ has not been noticed in the spectra of ferrocene in the halocarbon solvents before photoexcitations. However, in the spectra after photoexcitations a shoulder has been observed to appear at $\approx 530 \mathrm{~nm}$. The position of this band is close to the band peaked at $528 \mathrm{~nm}$, assigned by Scot and Becker ${ }^{15}$ as a spin forbidden singlet-triplet absorption corresponding to the forbidden singlet-singlet absorption at $324 \mathrm{~nm}$. Possibly the band peaked at $530 \mathrm{~nm}$ is the spin forbidden singlet-triplet absorption band of ferrocene, as assigned by Scott and Becker mentioned above. The appearance of the forbidden singlet-triplet absorption band of ferrocene peaked at $530 \mathrm{~nm}$ has become possible by photoexcitation. The process, by which the band appears through photoexcitation, may be termed perturbation. We do not mean the perturbation of energy levels of $\mathrm{FcH}^{+}$or generation of an entirely new species. But we believe that as a result of photoexcitation the forbidden singlet-triplet absorption band of ferrocene has become 'allowed'. Solutions of ferrocene in $\mathrm{CHCl}_{3}$ and $\mathrm{CCl}_{4}$ have shown other new absorption maxima at $\approx 290,362$ and $620-627 \mathrm{~nm}$. The band at 620 $627 \mathrm{~nm}$ is due to ferricenium ion ${ }^{12}$ and the bands at 290 and $362 \mathrm{~nm}$ appear due to organic radical (R) cations formed ${ }^{10-12}$ as a result of photoreaction. The formation of ferricenium ion $\left[\mathrm{FcH}^{+}\right]$and radical cation indicate that the new band appeared at $315 / 320 \mathrm{~nm}$ in halocarbon solvents $\mathrm{CHCl}_{3} / \mathrm{CCl}_{4}$ after photoexcitations originates due to ferrocene-to-solvent-charge-transfer (CTTS) transitions. The CT band overlaps with the bands of ions as well as ferrocene, which make this band broader (shoulder type).

It has been discussed earlier that in the UV region, the maximum intensity of the photoinduced changes was observed for irradiation at about 285 and $320 \mathrm{~nm}$ for ferrocene- $\mathrm{CHCl}_{3}$ and ferrocene- $\mathrm{CCl}_{4}$ systems, respectively. It is interesting to note that in the case of ferrocene- $\mathrm{CCl}_{4}$ system the maximum intensity of the photoinduced changes was noticed for irradiation at the wavelength corresponding to the position of the CTTS transition. But for the ferrocene- $\mathrm{CHCl}_{3}$ system the maximum intensity of the photoinduced changes was observed for irradiation at $285 \mathrm{~nm}$ while the position of the CTTS transition was at $315 \mathrm{~nm}$. The overall profile of the action spectrum for the photoinduced changes is possibly related to the solvent effect.

The primary step in the photoprocess is the dissociation of the CTTS state to give ferricenium cation $\left[\mathrm{FcH}^{+}\right], \mathrm{Cl}^{-}$and organic radical ion $\left(\mathrm{CHCl}_{2}\right.$. in the case of $\mathrm{CHCl}_{3}$ and $\mathrm{CCl}_{3}$. in the case of $\left.\mathrm{CCl}_{4}\right)^{3}$. On the basis of the results one could consider the following primary photochemical process:

$$
\mathrm{FcH}+\mathrm{RCl} \stackrel{h v}{\longrightarrow} \mathrm{FcH}^{+}+\mathrm{Cl}^{-}+\mathrm{R}
$$

for the formation of ferricenium ion and this process occurs through CTTS excitation. In fact, the real mechanism of the photoinduced processes involved is much complicated. It is not possible to monitor this from the present spectral studies.

Considering Mulliken's theory for formation of a charge-transfer complex, to a first approximation one can relate the energy of the charge-transfer band with the ionization 
potential of the donor and the electron affinity of the acceptor molecule by the linear relation ${ }^{16}$ :

$$
h v_{\mathrm{CT}}=I_{\mathrm{D}}^{\mathrm{v}}-E_{\mathrm{A}}^{\mathrm{v}}+\mathrm{C}_{1}
$$

where, $h v_{\mathrm{CT}}$ is the energy of the lowest-energy intermolecular charge-transfer band, $I_{\mathrm{D}}{ }^{\mathrm{v}}$ is the vertical ionization potential of the donor, $E_{\mathrm{A}}{ }^{\mathrm{v}}$ is the vertical electron affinity of the acceptor and $\mathrm{C}_{1}$ is a constant. If charge-transfer complexes of different donor molecules are formed with a common acceptor molecule, according to (2) a plot of $h v_{\mathrm{CT}}$ against $I_{\mathrm{D}}{ }^{\mathrm{v}}$ is expected to be linear with a slope of unity. Unfortunately, reliable values of vertical ionization potential and electron affinities are very scarce. Apart from the necessary distinction between the vertical and adiabatic or absolute values, different experimental methods yield different results, and also sometimes the substance of interest has not been studied at all. Usually for the practical purposes, the ionization potentials are considered as $I_{\mathrm{D}}$.

The formation of charge-transfer complexes of different electron donors with $\mathrm{CCl}_{4}$ has been reported in the literature ${ }^{17,18}$. For a ready reference the positions of the chargetransfer band observed for the $\mathrm{CT}$ complexes of $\mathrm{CCl}_{4}$ with different donor molecules are shown in table 1. The values of $I_{D}$ of the donors including the references are also presented in this table 1 . A plot of $h v_{\mathrm{CT}}$ against $I_{\mathrm{D}}$ for the CT complexes of $\mathrm{CCl}_{4}$ with different donor molecules is shown in figure 6 . A satisfactory straight line as predicted by (2) is obtained. The use of charge-transfer spectra for the evaluation of ionization potentials is well known. Now, if the new band at $320 \mathrm{~nm}$ observed for the solution of ferrocene in $\mathrm{CCl}_{4}$ after photoexcitation arises due to the formation of CT complex of ferrocene with the solvent $\mathrm{CCl}_{4}$, one can estimate the value of $I_{\mathrm{D}}$ of ferrocene with the help of the linear plot in figure 6 considering the value $(3.87 \mathrm{eV})$ of $h v_{\mathrm{CT}}$ corresponding to the band at $320 \mathrm{~nm}$. The value of $I_{D}$ estimated for ferrocene from figure 6 is $6.05 \mathrm{eV}$. The experimentally measured (photoionization threshold) value of $I_{\mathrm{D}}$ of ferrocene is reported ${ }^{23}$ to be $6 \cdot 1 \mathrm{eV}$. The excellent agreement between the values of estimated and experimental $I_{\mathrm{D}}$ of ferrocene supports the charge-transfer concept for the complex between ferrocene and $\mathrm{CCl}_{4}$ (after photoexcitation) under study and also supports the new band at $320 \mathrm{~nm}$ observed for the solution of ferrocene in $\mathrm{CCl}_{4}$ after photoexcitation to be the CTTS band. From (2) one expects a slope of unity for the $h v_{\mathrm{CT}}-$ versus $I_{D}$ plot. The linear plot in figure 6 gives a slope of $0 \cdot 60$. This low value for the slope could be due

Table 1. Position of the charge-transfer (CT) band observed for the CT complexes of $\mathrm{CCl}_{4}$ with different donor molecules.

\begin{tabular}{lccc}
\hline Donor & $\begin{array}{c}\text { Position of } \\
\text { CT band (nm) }\end{array}$ & $\begin{array}{c}\text { Value of } \\
h v_{\mathrm{CT}}(\mathrm{eV})\end{array}$ & $\begin{array}{c}\text { Value of } \\
I_{\mathrm{D}}(\mathrm{eV})\end{array}$ \\
\hline Benzene & $216^{17}$ & $5 \cdot 74$ & $9 \cdot 24^{19}$ \\
$m$-Xylene & $230^{17}$ & $5 \cdot 39$ & $8 \cdot 59^{19}$ \\
-Xylene & $230^{17}$ & $5 \cdot 39$ & $8 \cdot 44^{19}$ \\
Mesitylene & $235^{17}$ & $5 \cdot 28$ & $8 \cdot 39^{19}$ \\
Hexamethylbenzene & $242^{17}$ & $5 \cdot 15$ & $8 \cdot 00^{20,21}$ \\
Tetracene & $285^{\# 18}$ & $4 \cdot 35$ & $6 \cdot 94^{22}$ \\
\hline
\end{tabular}

"Value estimated from ref. 18 


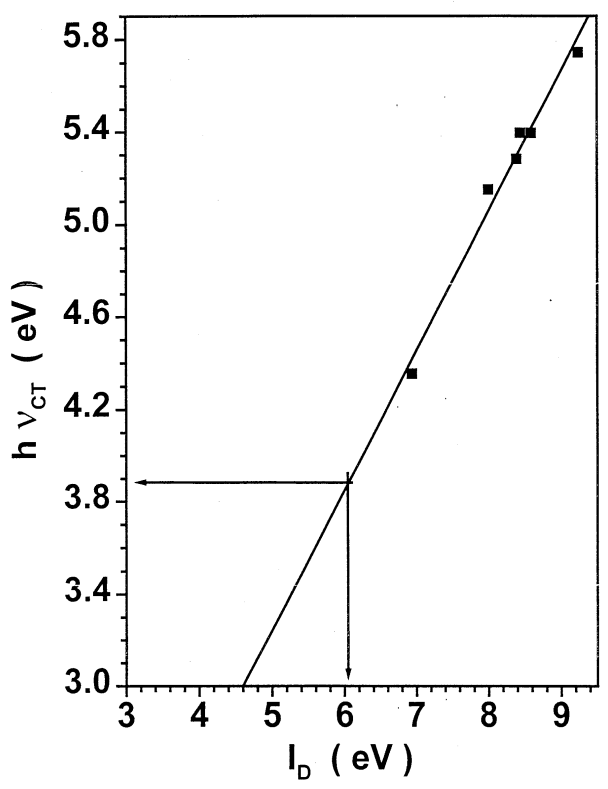

Figure 6. Plot of $h v_{\mathrm{CT}}$ versus $I_{\mathrm{D}}$ for the charge-transfer (CT) complexes of different electron donors with $\mathrm{CCl}_{4}$ as an electron acceptor. The horizontal and vertical arrows indicate the position of the CT band in the case of the CT complex of ferrocene with $\mathrm{CCl}_{4}$ and the value of estimated $\mathrm{I}_{\mathrm{D}}$ for ferrocene, respectively.

to the fact that ionization potential values used for the plot were not vertical values. Further, (2) is only an approximate one. Indeed, such a deviation of slope from unity is a general observation in these types of experiments ${ }^{24-26}$. McConnel et $\mathrm{l}^{25}$ have mentioned that the slope may have any value between $0 \cdot 4-1 \cdot 0$. It has been indicated by Foster ${ }^{26}$ that a large deviation from straight line of unit gradient in a plot like (2) can appear if the electron donor is only weakly effective. In the case of all-trans- $\beta$-carotene, the plot of CT band energy against electron affinity of some acceptor molecules was reported ${ }^{24}$ to be linear with a slope of 0.44 . But the ionization potential evaluated $(5.44 \mathrm{eV})$ for all-trans$\beta$-carotene agreed $^{24}$ well with the experimental value estimated $(5.5 \mathrm{eV})$ from photoemission threshold. Thus, the matching of the calculated ionization potential of ferrocene with experimental value is not accidental. If the band at $307 \mathrm{~nm}$ for the solution of ferrocene in $\mathrm{CCl}_{4}$ is considered as CTTS band as suggested by the previous research workers, the estimated value of $I_{\mathrm{D}}$ for ferrocene from figure 6 appears to be $6.32 \mathrm{eV}$, which cannot give better agreement with the experimental value $(6 \cdot 1 \mathrm{eV})^{23}$. Thus, the excellent agreement between the estimated value and the experimentally measured value of ionization potential indicates the exactness of the located band position for the CTTS transition in the case of the solution of ferrocene in $\mathrm{CCl}_{4}$. It has been mentioned earlier that the new band appeared at $315 \mathrm{~nm}$ in the case of $\mathrm{CHCl}_{3}$ after photoexcitation originates due to ferrocene-to-solvent charge-transfer (CTTS) transition. This data could not be utilized for identifying the CTTS position for the ferrocene- $\mathrm{CHCl}_{3}$ interaction (as in figure 6 in the case of ferrocene- $\mathrm{CCl}_{4}$ interaction) because the data available for the reported well resolved charge-transfer band for the CT complexes of $\mathrm{CHCl}_{3}$ with different donor molecules are inadequate. 


\section{Conclusion}

Changes in the electronic absorption spectra of ferrocene in the solutions of halocarbon solvents $\left(\mathrm{CHCl}_{3}\right.$ and $\left.\mathrm{CCl}_{4}\right)$ have been observed under photoexcitations by $\mathrm{UV}$ light in the nitrogen atmosphere. Using Mulliken's theory for the formation of a charge-transfer complex and considering the new band position $(320 \mathrm{~nm})$ for CTTS transition in the case of carbontetrachloride, ionization potential of ferrocene has been estimated. The estimated value has shown excellent agreement with the experimental value. Experimental results show that the new band appeared at $\approx 315$ and $320 \mathrm{~nm}$ in the electronic absorption spectrum of ferrocene in the solutions of $\mathrm{CHCl}_{3}$ and $\mathrm{CCl}_{4}$, respectively, after photoexcitation originates due to the CTTS transition under photoexcitation.

\section{Acknowledgement}

The authors would like to thank Prof. A Basuray, Department of Applied Physics, Calcutta University, Calcutta for the loan of the Luxmeter.

\section{References}

1. Carraher C E, Sheets J E and Pittman C U 1982 Advances in organometallic and inorganic polymer science (New York: Marcel Dekker)

2. Turner A P F, Karube I and Wilson G S (eds) 1987 Biosensors (London: Oxford Univ. Press)

3. Geoffroy G L and Wrighton M S 1979 Organometallic photochemistry (New York: Academic Press) p. 242

4. Meier H 1974 Organic semiconductors (Weinheim: Verlag Chemie) p. 165

5. Gutmann F, Keyzer H and Lyons L E 1983 Organic semiconductors (Malabar, FL: Krieger) part B, pp. 360, 463

6. Ozaki J, Watanabe T and Nishiyoma Y 1993 J. Phys. Chem. 971400

7. Mallik B and Chakraborty A K 1996 J. Phys. Chem. 1002145

8. Mallik B and Chakraborty A K 1997 J. Chem. Soc., Faraday Trans. 933677

9. Chakraborty A K and Mallik B 1995 Synth. Met. 73239

10. Akiyama T, Sugimori A and Hermann H 1973 Bull. Chem. Soc. Jpn. 461855

11. Traverso O and Scandola F 1970 Inorg. Chim. Acta 4493

12. Brand J C D and Snedden W 1957 Trans. Faraday Soc. 53894

13. Augustyniak A J and Wojtezak J 1984 Trans. Metal Chem. 9303

14. Tatistcheff H B, Hancock L F and Wrighton M S 1995 J. Phys. Chem. 997689

15. Scott D R and Becker R S 1961 J. Chem. Phys. 35516

16. Chen E C M and Wentworth W E 1975 J. Chem. Phys. 633183

17. Kellawi H and Rosseinsky D R 1969 J. Chem. Soc. (A) 1207

18. Davis K M C and Farmer M F 1968 J. Chem. Soc. (B) 859.

19. Gutmann F and Lyons L F 1967 Organic semiconductors (New York: John Wiley) p. 680

20. Meyer F and Harrison A G 1964 Can. J. Chem. 422256

21. Foster R 1969 Organic charge-transfer complexes (London and New York: Academic Press) p. 384

22. Gutmann F, Keyzer H and Lyons L E 1983 Organic semiconductors (Malabar, FL: Krieger) part B, p. 497

23. Gutmann F, Keyzer H and Lyons L E 1983 Organic semiconductors (Malabar, FL: Krieger) part B, p. 501

24. Mallik B, Jain K M and Misra T N 1980 Biochem. J. 189547

25. McConnel H, Ham J S and Platt J R 1953 J. Chem. Phys. 2166

26. Foster R 1960 Tetrahedron 1096 